\title{
Imigração em Portugal ${ }^{1}$
}

\author{
IGOR JOSÉ DE RENÓ MACHADO
}

\section{A imigração brasileira em Portugal, 2005}

$\mathrm{E}$ M PORTUGAL, a presente migração brasileira representa tanto uma continuidade com padrões mais antigos como uma novidade. Ela pode ser vista como "lusófona" (com todos os reparos que se pode e deve fazer a essa nomenclatura) (Margarido, 2000), ou seja, guarda relações com as migrações de outros ex-sujeitos coloniais. Por sua vez, a imigração brasileira pode ser também colocada ao lado das novas migrações para Portugal, juntamente com as "imigrações de leste". À semelhança desse novo fluxo, a movimentação de brasileiros revela uma intensidade e uma vitalidade que fazem desse movimento algo em constante expansão. Veremos, porém, que a lógica do tratamento dado aos imigrantes brasileiros tem mais relação com as ordens estabelecidas desde o Império do que com os desafios que a "nova imigração" do Leste europeu coloca a esse quadro cognitivo.

Neste artigo, analisaremos a relação entre as ordens hierárquicas de alteridades, herdeiras do império e a atual situação da imigração em Portugal. Veremos como as políticas respondem às ordens preestabelecidas e, ao mesmo tempo, encarceram os diversos grupos de imigrantes em categorias étnicas/raciais, promovendo oficialmente um "gerenciamento da diferença" que resulta tanto no obscurecimento de um conhecimento efetivo das populações imigrantes em Portugal como numa impossibilidade de integração à sociedade portuguesa.

\section{Hievarquia e etnicização}

A intenção, nesta parte, é indicar o contexto simbólico no qual se inserem e são inseridos os brasileiros, de forma a precisar qual é e como foi formada a "hierarquia das alteridades" portuguesa, ou seja, a estrutura simbólica que escalona em termos de status as diferentes populações em Portugal. Entendo que a colonialidade do poder (Grasfoguel \& Chloe, 2000; Quijano 1998), ou seja, a manutenção das estruturas racial-hierárquicas que permearam toda a reflexão imperial portuguesa, seja responsável pela perenidade de uma forma racializada de encarar a diferença, mas agora reconstruída em termos étnicos. Em outras palavras: os sujeitos de diferentes nacionalidades que emigraram para Portugal até meados da década de 1990 encontraram uma escala na qual foram inseridos, principalmente pelo fato de que até 1998 a maior parte da imigração em Portugal foi composta por gente das ex-colônias. A presença de imigrantes dos Palop (Países Africanos de Língua Oficial Portuguesa) e do Brasil em Portugal, majoritariamente, ${ }^{2}$ facilitou a perenidade do pensamento colonial. Essa perenidade resultou na reconstrução dentro de Portugal da antiga ordem imperial, agora reorganizada com base nas populações imigrantes. 
A organização simbólica das alteridades, ou seja, a forma como os sujeitos de diferentes nacionalidades e lugares são hierarquizados pela ideologia nacionalista (Fox, 1990) hegemônica em Portugal, é conseqüência do pensamento colonial português retomado após a perda do Brasil, em 1822, no período conhecido como o Terceiro Império. ${ }^{3}$ No século XX, esse pensamento, fundado em convicções evolucionistas, disfarçou-se nas teorias do lusotropicalismo (à portuguesa) e, atualmente, na lusofonia (Castelo, 1998; Alexandre, 1998, 2000). Enfim, a experiência do Terceiro Império (Thomaz, 1997) é fundamental para entender a configuração do universo simbólico no qual se inserem os brasileiros, e como nele o Brasil tem uma função específica - a de exemplo para a África portuguesa - que influenciará a forma como ele é considerado e como seus imigrantes serão inseridos na vida portuguesa (Machado, 2003).

Hoje em dia, a lusofonia acaba por reforçar as hierarquias coloniais, nas quais o Brasil ocupa um lugar intermediário entre africanos e portugueses. Ora, esse processo vai refletir-se diretamente na vida dos imigrantes brasileiros. Uma das conseqüências dessa hierarquização é que os estereótipos sobre brasileiros vigentes em Portugal atuam como uma prisão. Constantemente submetidos às representações solidificadas pela hierarquia racial, comuns em Portugal, muitos imigrantes brasileiros acabam por representar papéis preestabelecidos e, como veremos adiante, são "etnicizados" pelo discurso político e legislativo português. ${ }^{4}$ Uma suposta "essência” do brasileiro passa a ser algo real, capital cultural "encontrável”, ou seja, cultura objetivada. Por conta dessa objetivação, a presença dos brasileiros é mais notada no que é considerado "hotelaria”, que são os serviços de restaurantes, casas noturnas, bares e lojas de atendimento em geral. Os brasileiros são aproveitados em razão da necessidade do mercado de trabalho e da predisposição simbólica que os encaixa em determinada categoria. Mas é também fato que os brasileiros ocupam cada vez mais postos de trabalho na construção civil e no serviço doméstico (Peixoto \& Figueiredo, 2005; Padilla, 2004), processo que tem ficado à margem da percepção portuguesa sobre a imigração brasileira.

O universo simbólico português é, portanto, marcado por densas representações sobre o Brasil. Quando imigrantes brasileiros lutam por direitos especiais, apelando à lusofonia (na idéia de que há uma fraternidade entre os que falam português), reforçam o lugar subalterno que determinadas conotações dessa ideologia lhes conferem e, de certa forma, legitimam o discurso oficial do Estado, baseado em percepções de uma diferença estrutural e constante, etnicizada (Feldman-Bianco, 2001). Os brasileiros ocupam um lugar especial, pela sua posição privilegiada na hierarquia racial, embora subalterna. Esse lugar especial na hierarquia é composto por uma série de representações sobre o Brasil que derivam do denso campo simbólico que envolve o Brasil em Portugal. Os resultados desse lugar são os processos de exotização (Machado, 2003), por um lado, e, por outro, a equalização do olhar sobre o brasileiro, como demonstro a seguir. 


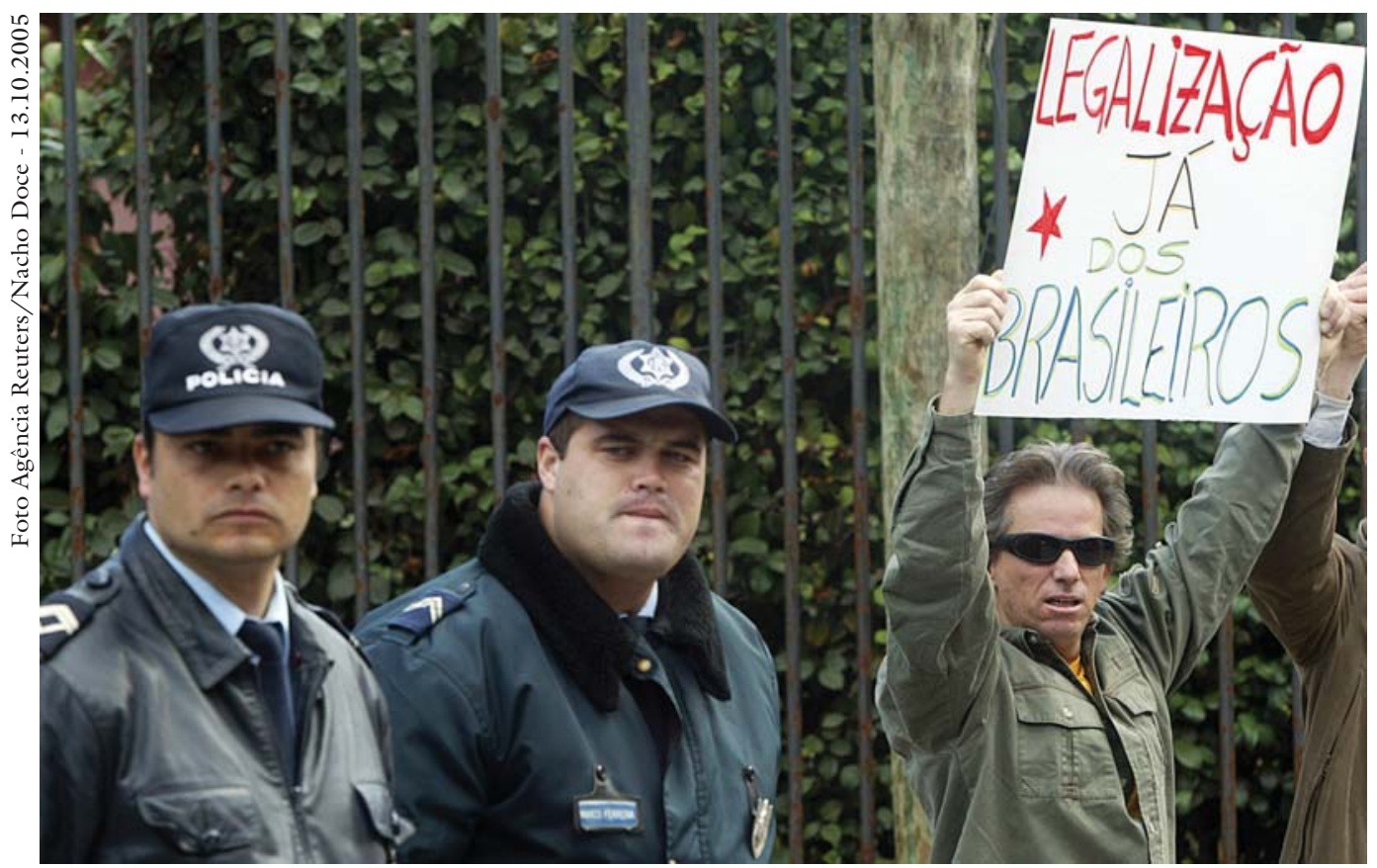

Protesto de brasileiro na cidade de Porto, Portugal, durante reunião entre os dois governos.

\section{Europeus "de leste"}

Até aqui tratamos de um quadro imigratório que "faz sentido" a partir do pensamento imperial. Mas, desde meados da década de 1990, essa normalidade classificatória tem sido ameaçada pela presença de imigrantes que desafiam esse quadro lógico. Imigrantes do "leste europeu", nome que inclui uma variedade de populações nacionais distintas - russos, ucranianos, moldavos, romenos, entre outros -, têm migrado em grandes contingentes para Portugal. Durante um espaço de tempo significativo, entre 2001 e 2003, os ucranianos assumiram o posto de nacionalidade de imigrantes mais numerosos em Portugal - lugar logo depois destinado aos brasileiros. Mas, se lembrarmos que em 2000 a presença desses migrantes do "leste europeu" em Portugal era inexpressiva, teremos uma dimensão da intensidade do fluxo, pois, de inexpressivos, os ucranianos, por exemplo, passaram a uma das principais comunidades imigrantes em Portugal.

Mas o fato que nos interessa neste texto é que a população do "leste" escapa à normalidade classificatória lusófona, pois são pobres e brancos e, muitos deles, altamente qualificados. Como essa população passa a ser pensada pela sociedade portuguesa é um assunto para reflexões mais sistemáticas, coisa que não posso fazer neste espaço. Basta dizer, para nossos interesses, que eles são conscientemente colocados à margem dos discursos sobre imigração, como se não fossem tão significativos como são.

Um trabalho apresentado por Lages \& Policarpo $(2003)^{5}$ e apoiado pelo Alto Comissariado para Imigração e Minorias Étnicas (Acime), ilustra bastante bem o que chamo de hierarquias de alteridade, ao levantar, por meio de pesquisas estatisticamente válidas, a opinião geral de portugueses sobre os imigrantes 
em Portugal. A entrevista foi aplicada a cerca de 1.400 portugueses: as categorias utilizadas representam em si uma construção étnica/racial, que discutiremos mais adiante. Em todas as dimensões, vemos uma reordenação hierárquica dos níveis classificatórios: os "de leste" entram numa posição intermediária entre brasileiros e africanos. Essa pesquisa levanta claramente como o lugar dos imigrantes "de leste" num quadro de hierarquias portuguesas é ainda incerto: na maior parte das respostas, eles encontram mais aceitação que os africanos. Em todas as perguntas, os brasileiros recebem uma certa preferência.

O trabalho de Lages \& Policarpo indica como prevalece um "racismo tradicional", racializado: há uma dificuldade maior em aceitar imigrantes africanos grande parte deles negros e, de qualquer maneira, considerados negros no pensamento imperial (Castelo, 1998) - que os recém-chegados brancos e pobres. As próprias categorias de análise, embora oficialmente étnicas, são racializadas: em geral, o português entende o termo "africano" como sinônimo de "negro". Mas há diferenças de cores entre os africanos de cada país e de país a país, como é óbvio. O termo acaba por apagar as diferenças imensas entre os africanos, ao mesmo tempo que os submete a um regime de disfarçada racialização. O mesmo se pode dizer em relação aos imigrantes do "leste europeu".

\section{Etnicização}

Vemos que o uso cotidiano da idéia de "etnicidade" se atrela às hierarquias: o termo brasileiro vira o sinônimo de Uma etnicidade, significando um estoque de diferença contido pela própria definição. $\mathrm{O}$ mesmo acontece de forma mais radical com outros grupos imigrantes, pois todos os "leste europeus" viram Uma única etnicidade. Nesse sentido, o brasileiro tem privilégio, pois é nacionalizado em oposição aos "africanos" e "do leste". Percebe-se claramente que o discurso cotidiano sobre etnicidade - poderíamos dizer sua existência sociológica - nada mais é que uma forma de uso politicamente correto da idéia de raça.

Especificamente em relação aos imigrantes de leste, o que se vê é que a anormalidade classificatória os exclui sistematicamente. Eles colocam, digamos assim, um desafio às ordens construídas. Esse desafio é sentido no último lugar da fila que lhes é concedido em termos de reivindicação de direitos. E mais do que isso, o que os discursos oficiais de Estado e os do senso comum indicam (pensamos aqui nos textos das leis e no discurso da mídia, principalmente) é que a construção da categoria "imigrantes de leste" é um esforço para normalizar essa dificuldade.

Tem-se notado que os discursos étnicos produzidos por fontes oficiais tendem simplesmente a trocar as antigas categorias raciais por novas categorias étnicas: assim, negros transformaram-se em "africanos", mestiços em "brasileiros". A categoria "africano" é, obviamente, uma categoria que esconde uma diversidade muito grande de nacionalidades (cabo-verdianos, moçambicanos, angolanos, quineenses), que expressam diferentes realidades, mesmo classificatórias. Entre as nacionalidades, há um certo grau de maior e menor negritude atribuída, processo que tem sido equalizado na categoria étnica/oficial de 
“africanos". Os brasileiros, por sua, vez, comprovando seu status relativamente privilegiado, são os únicos a serem classificados por um termo nacional, transformado em categoria étnica pelo discurso oficial. ${ }^{6}$ Os brasileiros são únicos a verem sua nacionalidade preservada como índice classificatório, perante a condição que ela se transforme numa categoria étnica/racial que restabeleça um lugar determinado para a população rotulada: um lugar intermediário entre os demais imigrantes e a população portuguesa.

Até a chegada dos imigrantes "do leste", branquitude era sinônimo de portuguesidade. A categoria "leste" serve para manter a definição "branco = português" operante. O termo geograficamente vago "leste" tem implicações simbólicas que não podem ser desprezadas: ele implica uma distância insuperável, remetendo à idéia de "Oriente", tão bem analisada por Said (1990). De certa forma, o termo expulsa simbolicamente os "do leste" da Europa e os localiza num oriente mais remoto e exótico; a idéia de "leste" tem conotações políticas muito marcadas pela recente história da guerra fria, como é óbvio, e denota algo como sistemas políticos perversos, suspeição que é dirigida aos imigrantes (um certo receio da imagem de superespecialização educacional desses imigrantes). Baganha et al. (2004, p.33) afirmam que

when compared to the Portuguese active population and to the immigrant population form Third Countries, these immigrants show an extremely high level of education. In fact $69 \%$ had completed high school or professional/technical school. $10 \%$ had a bachelor or equivalent and $21 \%$ had graduate studies. *

Há um certo medo em relação às qualificações dos imigrantes "de leste", como atestam Lages \& Policarpo (2003, p.7), em sua sondagem aos portugueses:

Ainda assim, apenas uma minoria de inquiridos receia que "os imigrantes venham a ocupar lugares de maior importância que muitos portugueses" (em média 17,5\%). Mais uma vez, porém, se faz notar uma diferença importante entre os três grupos: $23,4 \%$ de inquiridos têm este receio relativamente aos imigrantes de Leste; este receio diminui relativamente aos brasileiros (16\%) e aos africanos (13,2\%).

Enfim, a categoria "étnica" "leste europeus" é uma forma tácita de racialização, que implica desbranquear esses imigrantes. Ela exclui os “de leste" da branquitude implícita à portuguesidade nas categorizações dos outros - portugueses não são nem africanos (negros), nem brasileiros (mulatos) e, agora, nem "de leste".

\footnotetext{
* “Quando comparados à população ativa portuguesa e à população de países terceiros, esses imigrantes apresentam uma escolaridade extremamente alta. De fato, 69\% terminaram o ensino médio ou cursaram escolas técnicas. Dez por cento têm curso de graduação ou equivalente e $21 \%$ têm pós-graduação". (Tradução nossa).

Comentário nosso: Os autores certamente se enganaram quanto ao número de imigrantes com alguma graduação, pois a própria tabela que exibem à página 33 indica que os $21 \%$ que têm alguma pós-graduação (lato ou stritu sensu) são também portadores de algum título de graduação. Assim, o número de graduados seria algo em torno de $31 \%$.
} 


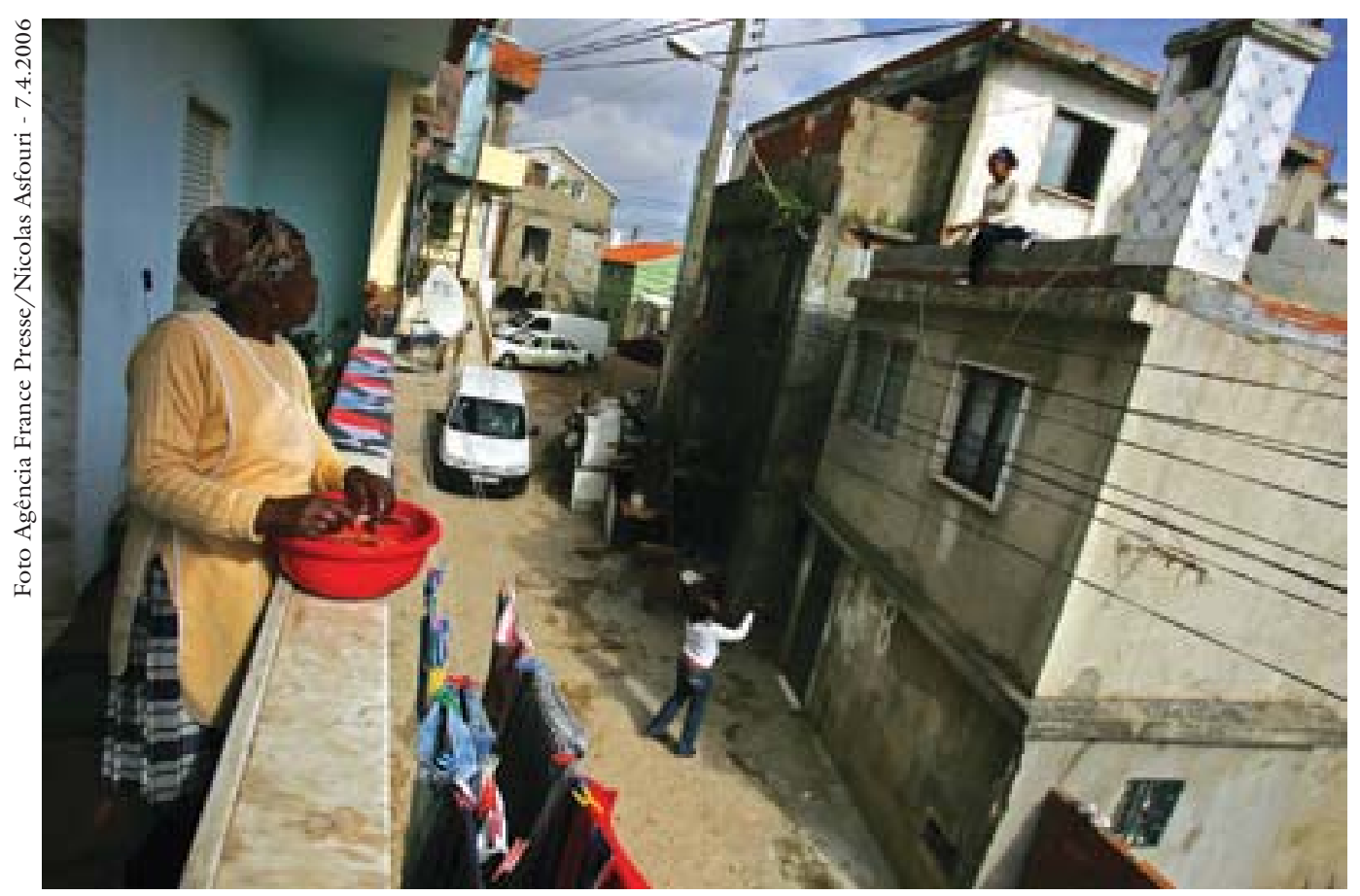

O bairro Cova da Moura, subúrbio de Lisboa, Portugal, concentra a população africana.

Se teoricamente a idéia de etnicidade aparece como um instrumento à dessubstancialização das identidades (Barth, Erikson etc.) e a sua conexão não a qualidades atávicas, mas a qualidades referenciais, distintivas e relativas, na prática da política portuguesa; porém, a etnicidade serve à re-racialização das diferenças,

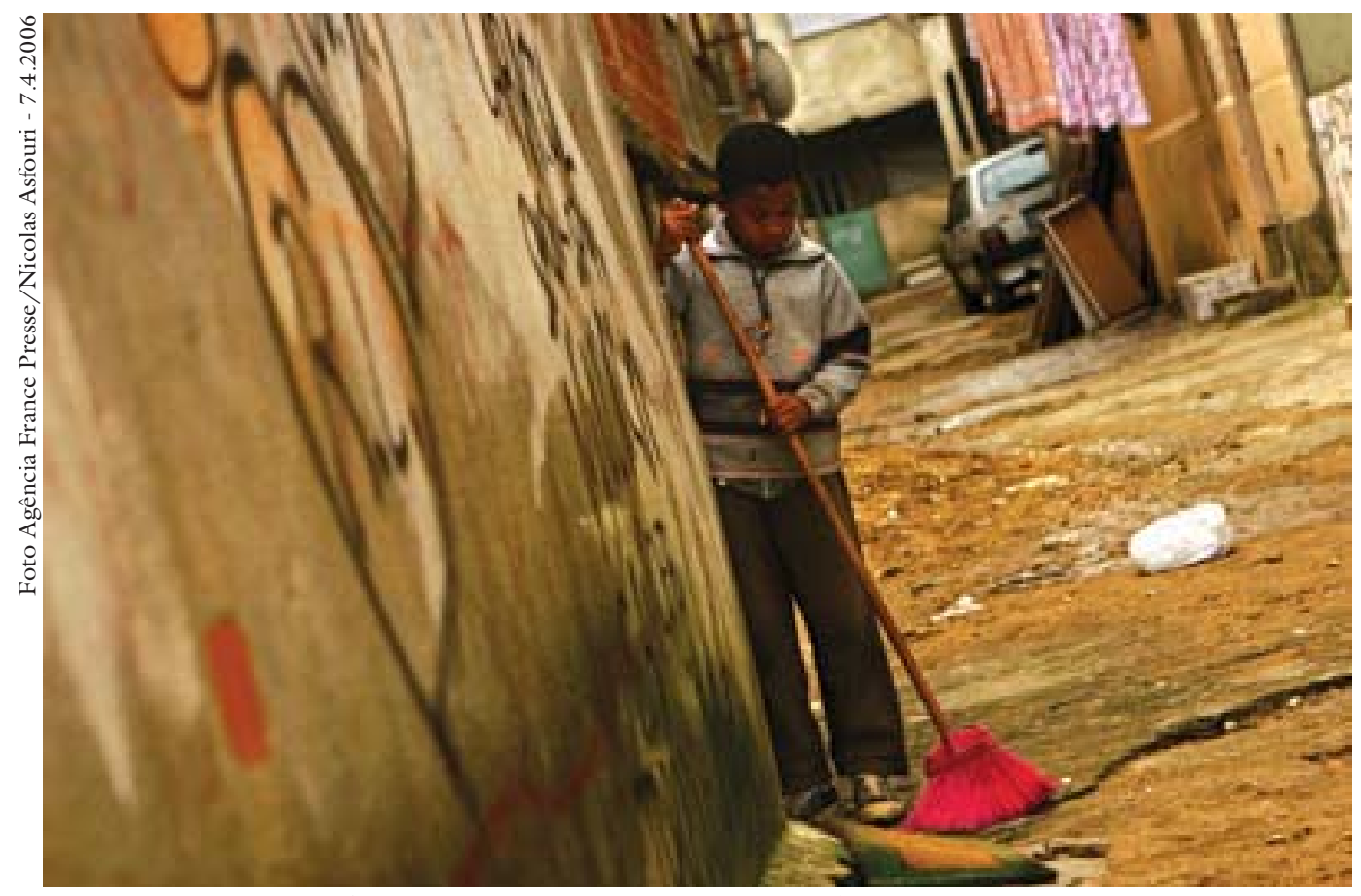

Um jovem de ascendência africana varre a rua no subúrbio de Cova da Moura, em Lisboa. 


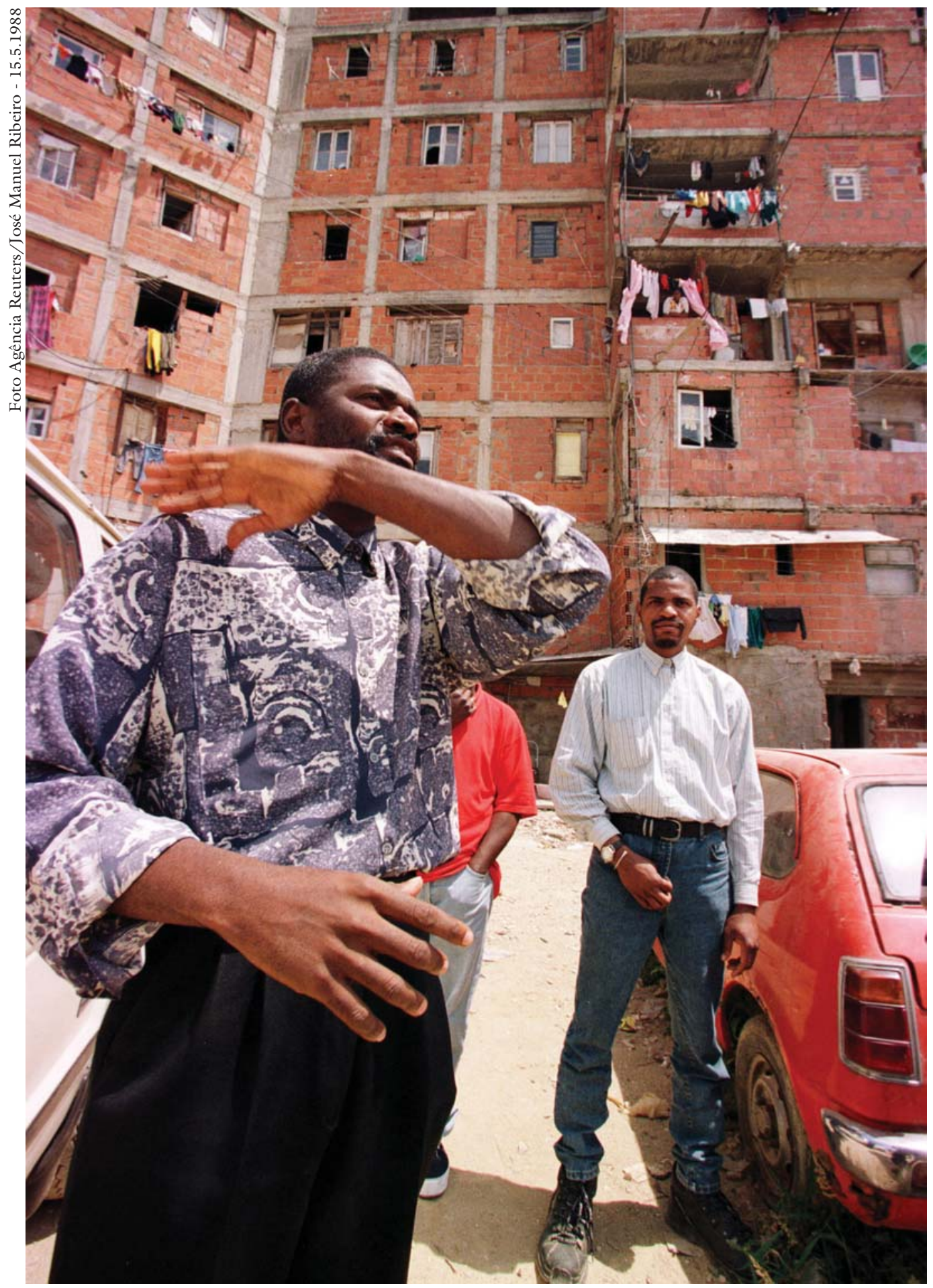

Um terço dos moradores da Quinta do Mocho, em Sacavém, é de nacionalidade angolana.

sendo apenas um outro nome mais socialmente aceitável para a atribuição de qualidades substantivas e imutáveis aos qualificados. Assim, o termo "africanos" carrega uma conotação negativa, "brasileiros" uma conotação sexualizada (Pontes, 2004; Machado, 2003; Padilla, 2004) e, agora, “do leste” uma conotação de suspeição. 
Por sua vez, os imigrantes de países ricos (Primeiro Mundo) não são exatamente considerados imigrantes, ou seja, eles não são etnicizados nem no discurso político nem no acadêmico. Enfim, eles são outra coisa (estrangeiros), e não minorias étnicas. Assim, os órgãos estatais que lidam com os imigrantes (como o Acime - alto comissariado para a imigração e minorias étnicas) tratam apenas daqueles em condições simbólicas de subalternidade.

\section{Etnicização e a diversidade dos brasileiros}

$\mathrm{O}$ processo de etnicização produz outros efeitos, além da exotização e reificação de identidades já mencionados: ele tenta impor uma versão "correta" da identidade brasileira, significando um obscurecimento das intensas diferenças que se produziram entre as diversas brasilidades em Portugal. As distintas formas de construção identitária dos brasileiros são subsumidas na imagem exotizada/etnicizada "oficial". Como exemplo dessa diversidade, contraponho dois processos alternativos e distintos de construção de brasilidades em Portugal: um que é inflexionado pela exotização e outro que passa à margem desse processo.

Inúmeras variáveis apontam para um fato do qual não podemos escapar ao tratar do fenômeno da migração brasileira em Portugal: tratamos não de uma, mas de várias identidades. As identidades brasileiras construídas a partir da experiência da imigração são distintas entre si, cortadas por: 1) questões de classe entre a população imigrante, 2) por questões de temporalidade da imigração, 3 ) por questões de gênero e sexualidade, 4) de ascendência portuguesa (por sua vez diferenciada por graus diferentes de ascendência), 5) por questões de cor/ raça, 6) por questões de ocupação no mercado de trabalho, 7) por questões de origem regional e, finalmente, 8) questões de religião, entre outras possíveis.

Citei ao menos oito diferentes eixos de clivagem nos processos de construção de identidades brasileiras em Portugal. Levando em consideração que eles se combinam complexamente, formando configurações diferenciadas e posicionamentos diferentes e que outros eixos podem ser tão relevantes como esses, somos capazes de ter uma dimensão apropriada de como a idéia de Uma identidade brasileira na verdade esconde uma diversidade significativa de identidades que se constroem lentamente nesse contexto migratório. Pretendo, para ilustrar tal questão, citar rapidamente dois exemplos distintos dessa complexidade: vejamos as etnografias de Sérgio Oliveira (2004) e Igor Machado (2003). No meu trabalho de doutorado (Machado, 2003), trabalhei com algumas dimensões desses processos identitários. Falemos aqui daqueles que se referem aos processos de relações raciais entre os brasileiros imigrantes pobres no Porto, objeto de meu estudo.

Vimos antes que o Brasil aparece como uma espécie de modelo para os países colonizados em África e uma espécie de irmão mais velho dos países africanos sob dominação portuguesa. A esse discurso hierarquizador, foram alocadas características raciais, associadas às populações desses países. Assim, o Brasil, onde supostamente opera a democracia racial há mais tempo, seria um país mestiço, 
mulato. Os países africanos, ainda novos na experiência da mestiçagem (sempre seguindo o discurso ideológico), seriam, portanto, mais pretos. O Império se foi, mas ficaram os quadros classificatórios que o regularam. Assim, a "velha" imigração lusófona foi incorporada nessa lógica, e aos sujeitos imigrantes foram alocadas as classificações coloniais. O brasileiro aparece, portanto, à lógica da classificação, como mulato. Na prática dos imigrantes, essas classificações portuguesas produzem realidades e transformações quanto às relações sociais que se construíam no Brasil. Muito sucintamente, o que acontecia entre os brasileiros no Porto era uma preferência, por parte dos empregadores portugueses, por brasileiros mulatos para determinados tipos de trabalho.

Assim, os brasileiros mulatos, que viveram uma experiência de "opressão racial" no Brasil, experimentaram uma situação inusitada: no Porto, eles tinham mais facilidade de encontrar empregos que imigrantes brasileiros brancos. Mesmo brasileiros negros tinham mais facilidade de conseguir vagas no mercado de trabalho que os brancos. Chamei esse processo de "inversão racial”, propiciada pela etnicização da hierarquia das diferenças portuguesa. Essa inversão racial foi a linha mestra das construções de identidade brasileira entre esses imigrantes, resultando em toda uma organização da vida cotidiana e dos circuitos de reciprocidade marcada pela importância que, de repente, foi concedida aos brasileiros mulatos e negros.

O resultado desse processo foi uma radicalização do discurso ideológico brasileiro da mestiçagem. É como se apenas em Portugal o sonho de uma sociedade mais justa racialmente fosse possível. É como se o Brasil pudesse ser um Brasil "de verdade" em Portugal. Ao redor desse processo, emerge uma identidade ultra-essencializada, preocupada em enfatizar todos os estereótipos sobre o que é o Brasil, como que numa forma de reafirmar constantemente aos portugueses que o Brasil é mesmo o lugar que eles imaginam. Assim, o processo identitário que resulta dessa conjuntura é a invenção de uma brasilidade radicalmente estereotipada, mas que tem existência real como motor de auto-identificação dos sujeitos imigrantes. Vemos que as questões de raça produzem conformações específicas nas construções identitárias dos brasileiros em Portugal. A esse processo estava ligada uma determinada posição no mercado de trabalho: afinal, o brasileiro deveria ocupar o lugar de feliz animador de uma eterna platéia portuguesa: músicos, dançarinos, atendentes ao público em geral.

Mas o que acontece quando o lugar no mercado de trabalho não se relaciona de forma alguma com os estereótipos de brasilidade? Passemos a examinar o caso dos brasileiros na Costa da Caparica, seguindo o trabalho de Oliveira (2004). O fato é que esses brasileiros trabalham predominantemente na construção civil. E a construção não tem nada de "abrasileirável" em si. Os processos de construção identitária passam então por outras determinantes. Mas deixemos claro que esses brasileiros são tão brasileiros como aqueles outros no Porto em 2000, apenas o são à sua maneira, o que ilustra, mais uma vez, a diversidade de identidades brasileiras em Portugal. O trabalho de Oliveira indica que há evi- 
dências muito fortes de que um número significativo desses brasileiros na Costa da Caparica é oriundo de uma mesma região no Brasil: a região de Governador Valadares, Minas Gerais.

Ora, essa região é sabidamente o maior centro brasileiro de emigração internacional, focada até pouco tempo atrás predominantemente na emigração para os Estados Unidos. Como um centro de emigração, já de longa data, o fenômeno da migração em si produz uma disposição a encarar a movimentação como parte natural da vida de uma pessoa. Diversos trabalhos sobre a emigração valadarense (Assis, 1995a, 1995b e 1999; Scudeler, 1999; Fusco, 2000 e 2001; Soares, 1995a, 1995b, 1999 e 2002) indicam como esse fenômeno é parte constituinte das produções identitárias locais: ou seja, emigrar é algo que ajuda a definir um valadarense. Um dos resultados dessa "cultura local” de emigração foi a constituição de redes muito sólidas e organizadas de contrabando de pessoas, especializadas em colocar imigrantes nos Estados Unidos. Processo esse que, todos sabemos, é extremamente lucrativo.

Em outro texto (Machado, 2004), procurei demonstrar como é a conexão entre a cultura migratória e essa indústria que produz em grande parte o fenômeno da Caparica: Portugal passou a ser uma opção viável para a emigração diante da dificuldade, dos custos e dos riscos de uma entrada clandestina nos Estados Unidos. Como passagem para os Estados Unidos com o auxílio de documentos portugueses falsificados ou como opção mais barata de imigração e ponte para outros lugares na Europa, Portugal foi um destino eleito como preferencial. Isso significa, na prática, que os brasileiros na Caparica têm um vetor muito importante para elaborar suas identidades: o vetor da regionalidade, da experiência cotidiana com a emigração.

Como provenientes de uma região como a de Valadares, com a idéia da movimentação como parte da identidade, esses brasileiros seguem caminhos diferentes nessa experiência portuguesa: Oliveira (2004) demonstra como é a experiência da "ilegalidade" $\mathrm{o}$ nexo mais relevante para a construção de identidades (que, lembremos, é um processo constante de reconstruções). A vivência da ilegalidade é o nexo central na produção de discursos sobre a realidade, desde o confinamento aos empregos na construção civil até a dificuldade em ir para os Estados Unidos. Ao mesmo tempo, a ilegalidade é vivida como algo normal, ou seja, como natural. Esse processo da ilegalidade como quase um fato do destino tem relações profundas com a "cultura da emigração" valadarense. Ou seja, temos aqui claramente uma situação em que a regionalidade opera como o nexo central na construção de uma identidade brasileira entre esses imigrantes, fato muito diferente do que acontecia no Porto, no exemplo anterior.

Lembremos que analisei até aqui apenas imigrantes predominantemente homens, e que a história seria diferente se me referisse às imigrantes mulheres. Os trabalhos de Beatriz Padilha (2004) e de Luciana Pontes (2004) dão indicações dessas especificidades de gênero, por exemplo. São muitas as possibilidades, nesse mar de identidades, como as levantadas por Ângela Torresan (2004) so- 
bre os imigrantes brasileiros de classe média, ou as trabalhadas por Clara Mafra (1999) em relação à religião. Isso para citar apenas alguns exemplos analisados em profundidade por esses autores. ${ }^{8}$

\section{Conclusões}

Vimos aqui as conseqüências de um discurso étnico vulgar no quadro mais geral da imigração portuguesa: analisamos como conduz a uma postura discriminatória em relação aos imigrantes que fogem ao "quadro normal" de alteridades, domesticado com a idéia de etnicidade a substituir a de raça. Analisamos como a etnicização conduz a um encarceramento do imigrante em uma identidade oficialmente chancelada pelas políticas governamentais, resultando num obscurecimento da diversidade interna das populações imigrantes. Demonstramos aqui um pouco dessa diversidade em relação aos imigrantes brasileiros em Portugal.

A relação evidente entre a noção de raça e etnia no discurso português pode-se perceber pela fala do organizador do I Congresso sobre Imigração em Portugal, promovido em 2003 pelo Acime. Da associação entre raça, etnia e cultura, passa-se à constatação de que Portugal vive uma "multiculturalidade". Políticas multiculturais tendem a encarcerar os subordinados em categorias estanques, chamadas ora de étnicas ora de culturais e até mesmo de raciais: ${ }^{9}$

Sempre tivemos minorias estrangeiras entre nós, mas nunca com a expressão e as características da presente imigração. Vêm de vários continentes, pertencem a várias raças e etnias, são portadores das mais diversas culturas, professam diferentes conviç̧ões religiosas, falam uma vasta pluralidade de línguas. De fenómeno episódico, quase imperceptível, a imigração passou a fluxo notório e marcante da nossa vivência colectiva, dotando a sociedade portuguesa de uma multiculturalidade que não conhecíamos no passado. (Cruz, 2003, p.15-6, grifo nosso)

Elas asseguram ao Estado, por exemplo, uma licitude na "gestão da diferença”, na expressão de Vala (2003), pois criam os estoques de diferenças legitimados e que devem se adequar às classificações. Assim, ucranianos devem se tornar "europeus de leste" para reivindicar direitos, e brasileiros devem se tornar etnicamente brasileiros, o que implica Uma representação legítima do que é brasilidade (já discutimos como essa monovalência representativa implica o obscurecimento das diferenças entre os brasileiros).

As palavras de Nuno Morais Sarmento (2003, p.17-9), ministro da Presidência, na mesma sessão de abertura desse congresso, devem ser lidas atentamente, para que entendamos as conseqüências e também os princípios de uma política multicultural oficial baseada numa idéia de etnicidade similar à de raça:

foi com base na nossa experiência colectiva e também na responsabilidade histórica de Portugal, que definimos alguns Princípios Orientadores das Políticas de Integração. Em primeiro lugar [...] é necessário assumir o combate à imigração ilegal $[\ldots] \mathrm{O}$ combate à imigração ilegal não nos impediu de garantir com coragem uma política humanista no que diz respeito à reunião familiar dos imigrantes [...] Por outro lado, quisemos também delinear uma politica de 
integração assente na valorização da diferença. Recusamos, pois, o princípio da assimilação, segundo o qual os imigrantes deverão ser como nós para poderem viver entre nós. Sabemos que todos temos a ganhar com uma sociedade heterogénea. O que nos une é o nosso destino, o objectivo para que nos dirigimos. Mais importante, pois, do que saber se viemos todos do mesmo local, é perceber para onde vamos. Todos. E quero aqui realçar que contamos com os imigrantes legais para a edificação de um novo Portugal. Todos estamos convocados e os imigrantes não serão excluidos. Em terceiro lugar, e na continuidade do que antecede, assumimos como um desafio a redução de conflitualidade e o combate da xenofobia [...] Queremos, além do mais, que a segunda geração se torne uma primeira prioridade na sociedade portuguesa, garantindo um acesso efectivo à educação e à saúde, mas também o acesso a oportunidades de formação de identidade e de realização pessoal. (grifo nosso)

Esse trecho do discurso do representante oficial do Estado português na abertura do citado congresso indica os caminhos de uma política multicultural/ étnica portuguesa: a aversão à “assimilação", a valorização e preservação da diferença, e constatação de que os imigrantes são co-autores do futuro de Portugal, mas sempre como Diferentes. Em seguida, uma constatação óbvia e derivada dessa política: os filhos dos imigrantes não são tratados como portugueses (embora o sejam), mas como "segunda geração". Assim, os imigrantes e seus descendentes devem e têm, na verdade, o dever de manterem-se diferentes. Resta ao governo garantir que, tendo os imigrantes se mantido diferentes, eles não sofram com a xenofobia, que deve ser combatida.

As categorias que regulam o debate prescrevem, portanto, que a diferença entre as populações é substantiva e que, sendo uma diferença substantiva, ela deve ser mantida para a montagem de um Estado heterogêneo. As categorias encerram tanto uma população como suas características culturais/etnicas/raciais: os filhos dos ucranianos devem continuar ucranianos (ou "leste europeus") para terem guarida do Estado, isto é, devem ser e permanecer diferentes. Obviamente, não defendemos uma política assimilacionista, como a mencionada pelo ministro, e não achamos que há apenas duas alternativas: ou se assimila ou se separa definitivamente. É claro, para mim, que os sujeitos devem escolher suas afinidades, e, se o filho de imigrante brasileiro sentir-se mais português, ele deverá ser tratado como tal pelo Estado português. Isso apenas para ficarmos na perspectiva do sujeito. Da perspectiva do Estado, conceder direitos a alguém porque ele é diferente, com a condição de que ele permaneça diferente, é claramente uma forma de não integrar e discriminá-lo. Se o imigrante passa a ser cidadão português (se ele se legaliza), ele deveria ser tratado pelo Estado como cidadão português e não como um "estoque de diferença" que serve à construção de um Estado heterogêneo. A política multicultural portuguesa é uma política de não-integração, baseada em preceitos racializados da diferença, encobertos pela idéia politicamente correta de "minorias étnicas".

Rui Pena Pires (2005), na sua fala no workshop "Migrações transatlânticas e transeuropéias", organizado por Beatriz Padilla e pelo ISCTE em 18 de março de 2005, afirmava que a recente política do Estado português resultava numa 


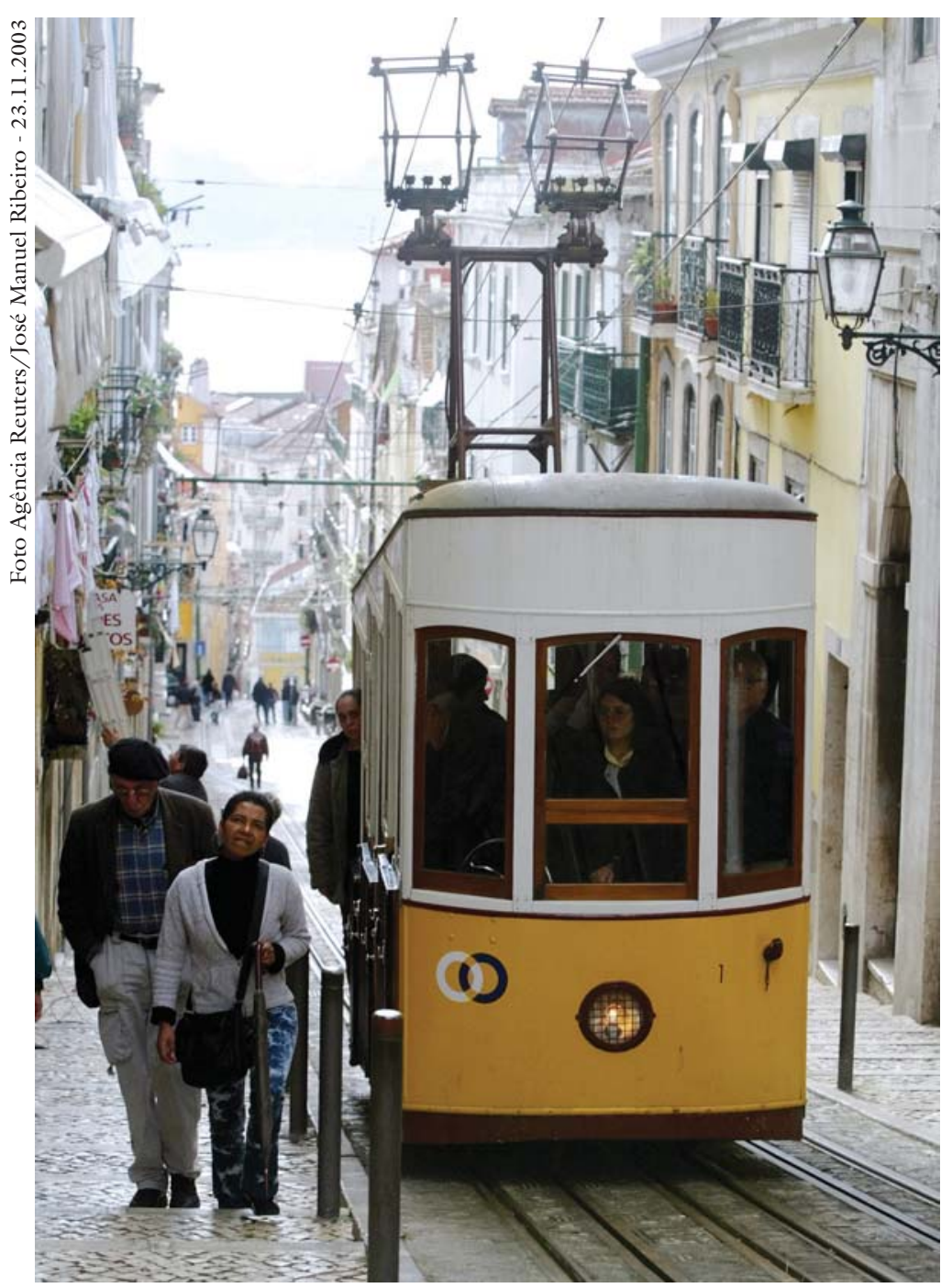

O bonde ajuda as pessoas a subir pelas ruas estreitas dos montes de Lisboa, em Portugal.

não-integração dos imigrantes, já que, de antemão, impedia a sua assimilação. Defendia, então, a possibilidade de uma "portuguesização" dos imigrantes. Parecemos aqui oscilar entre uma política "assimilacionista" e outra "multiculturalista", nos moldes colocados pelo ministro Nuno Sarmento. Ao colocar-lhe essa questão, Pires ofereceu uma resposta que nos livra dessa falsa dicotomia: defender a "aportuguesização" depende, necessariamente, de uma transformação no conceito de Nação Portuguesa, que deve alargar-se para aceitar as mudanças que uma integração de fato produzirá em seu seio. Ele coloca em questão o ponto neutro do qual as duas opções dicotômicas são construídas: o Estado que não quer ver sua portuguesidade transformada. Assim, o assimilacionismo propõe uma transformação de ucranianos, brasileiros, cabo-verdianos etc. em portugueses, enquanto o multiculturalismo propõe a aceitação dos diferentes, contanto que eles continuem diferentes e não desafiem a portuguesidade, que deve permanecer a mesma. Ao colocar o "ponto neutro" em questão, a idéia de 
Nação Portuguesa, podemos escapar à dicotomia: é necessário integrar e aceitar que a integração produzirá transformações tanto entre as populações imigrantes como na idéia de Nação Portuguesa.

Notas

1 Este texto é uma versão modificada e reduzida do artigo "Considerações sobre a construção de identidades brasileiras em Portugal e suas relações com categorias étnicas", apresentado na XXIX Anpocs, Caxambu, 2005.

2 Nos últimos cinco anos, entretanto, a situação tem mudado com a chegada de grandes contingentes de imigrantes do Leste europeu.

3 O Primeiro Império Português vai de 1450 a 1550, fundado no domínio das rotas marítimas para a Ásia. O Segundo Império, também conhecido como Luso-Brasileiro, dura de 1550 até 1822 , e é centralizado na exploração do Brasil. O Terceiro Império inicia-se na prática ao final do século XIX, com a colonização efetiva da África, mas pode ser pensado formalmente a partir do reconhecimento da independência brasileira, em 1825.

4 As afirmações referem-se sempre aos imigrantes de classe baixa e média baixa.

5 Posteriormente, este trabalho foi publicado como Lages \& Policarpo (2003). Cito aqui a versão provisória de 2002 .

6 Sobre a relação entre etnicidade e nacionalidade em contextos de migração, ver Ribeiro (1999).

7 Recorro ao termo ilegal por ser esse o utilizado, não sem discussões pertinentes, por Oliveira (2004). Para uma discussão sobre os termos referentes às populações imigrantes, ver De Genova (2002).

8 Para considerações mais abrangentes sobre a imigração brasileira em Portugal, ver Feldman-Bianco (2001).

9 Esse processo tem relações profundas com o que Vala (2003) chama de "hetero-etnicização".

\section{Referências bibliográficas}

ALEXANDRE, V. Introdução. In: CASTELO, C. O modo português de estar no mundo. O lusotropicalismo e a ideologia colonial portuguesa (1933-1961). Porto: Edições Afrontamento, 1988.

. Velho Brasil, novas Áfricas. Portugal e o Império (1808-1975). Porto: Afrontamento, 2000.

ASSIS, G. de O. Estar aqui, estar lá... o retorno dos emigrantes valadarenses ou a construção de uma identidade transnacional? Travessia - Revista do Migrante, ano 8, n.22, p.8-14, maio-ago. 1995a.

Estar aqui ... estar lá ... uma cartografia vida entre dois lugares. Florianópolis, 1995b. Dissertação (Mestrado em Antropologia Social) - Universidade Federal de Santa Catarina.

Estar aqui... estar lá...: uma cartografia da emigração valadarense para os EUA. 
In: REIS, R. R.; SALES, T. (Org.) Cenas do Brasil migrante. São Paulo: Boitempo, 1999. p.193-232.

BAGANHA, M. I. et al. The unforeseen wave: migration from eastern Europe to Portugal. In: BAGANHA, M. I.; FONSECA, M. L. (Ed.) New Waves: Migration from Eastern to Southern Europe. Lisboa: Fundação Luso-Americana, 2004.

CASTELO, C. O modo português de estar no mundo. O luso-tropicalismo e a ideologia colonial portuguesa (1933-1 961). Porto: Afrontamento, 1998. 166p.

CRUZ, M. B. Sessão de abertura. In: ALTO COMISSARIADO para a Imigração e Minorias Étnicas (Org.) Congresso Imigração em Portugal: Diversidade - Cidadania - Integração. Actas do I Congresso Imigração em Portugal: Diversidade - Cidadania - Integração. Lisboa: Acime, 2003.

DE GENOVA. N. P. Migrant "Illegality" and Deportability in Everyday Life. Anmual Review of Anthropology, v.31, n.1, 2002.

FELDMAN-BIANCO, B. Brazilians in Portugal, Portuguese in Brazil: constructions of sameness and difference. Identities Global Studies in Culture and Power, v.8, n.4, p.607-50, 2001.

FOX, R. Introduction. In: (Ed.) Nationalist Ideologies and the Production of National Cultures. American Ethnological Society Monograph Series, n.2, 1990.

FUSCO, W. Redes sociais na migração internacional: o caso de Governador Valadares. Campinas. Campinas, 2000. Dissertação (Mestrado em Sociologia) - Instituto de Filosofia e Ciências Humanas, Universidade Estadual de Campinas.

Redes sociais nas migrações entre Governador Valadares e os Estados Unidos. In: CNPD. Migrações internacionais - contribuições para política. Brasília: CNPD, 2001.

GRASFOGEL, R.; CHLOE, G. Coloniality of power and racial dynamics: notes towards a reinterpretation of latino caribbeans in New York city. Identities, v.7, n.1, p.85$125,2000$.

LAGES \& POLICARPO. Atitudes e valores perante a imigração. Lisboa: Acime e Observatório da Imigração, 2003.

MACHADO, I. J. R. Cárcere público: processos de exotização entre imigrantes brasileiros no Porto. Campinas, 2003. Tese (Doutorado) - Universidade Estadual de Campinas. Disponível em: <http://www.ufscar.br/ igor/public/carcere\%20publico\%204. pdf $>$.

Implicações da imigração estimulada por redes ilegais de aliciamento - o caso dos brasileiros em Portugal. Trabalho apresentado no VIII Congresso Luso-Afro-Brasileiro de Ciências Sociais, Coimbra, set. 2004. Disponível em: <http://www.ufscar. br/ igor/public/trafico\%20de\%20pessoas.pdf>.

MAFRA, C. C. J. Na posse da palavra: religião, conversão e liberdade pessoal em dois contextos nacionais. Rio de Janeiro, 1999. Tese (Doutorado) - PPGAS/MN.

MARGARIDO, A. A lusofonia e os lusófonos, novos mitos portugueses. Lisboa: Edições Universitárias Lusófonas, 2000.

OLIVEIRA, S. Espaços e tempo de ilegalidade: a construção quotidiana do imigrante ilegal. Trabalho apresentado no VIII Congresso Luso-Afro-Brasileiro de Ciências Sociais, Coimbra, set. 2004. 
PADILLA, B. Redes sociales de los brasileros recién llegados a Portugal: ¿solidariedad étnica o empatía étnica? Trabalho apresentado na Conferência Los Latinos al descubrimiento de Europa. Nuevas emigraciones y espacios para la ciudadanía. Génova, 17 y 18 de junio de 2004.

PEIXOTO, J.; FIGUEIREDO, A. Imigrantes brasileiros e mercado de trabalho em Portugal. In: MACHADO, I. (Org.) Um mar de identidades: imigração brasileira em Portugal. s. l.: s. n., 2005.

PIRES, R. P. O caso português. In: Workshop Migrações Transatlânticas e Transeuropéias. Realizado em 18 de março de 2005, no ISCTE, Lisboa.

PONTES, L. Mulheres imigrantes brasileiras em Lisboa. Portugal, 2004. (Mimeogr.).

QUIJANO, A. La colonialidade del poder y la experiencia cultural latinoamericana. In: BRICEÑO-LEON \& SONNTAG. (Ed.) Pueblo, época y desarrollo: la sociología de América Latina. Caracas: Nueva Sociedade, 1998.

RIBEIRO, G. L. O que faz o Brasil, Brazil: jogos identitários em São Francisco. In: REIS, R. R.; SALES, T. (Org.) Cenas do Brasil migrante. São Paulo: Boitempo, 1999. p.45-85.

SAID, E. Orientalismo. São Paulo: Cia. das Letras, 1990.

SARMENTO, N. M. Sessão de Abertura. In: ALTO COMISSARIADO para a Imigração e Minorias Étnicas. (Org.) Congresso Imigração em Portugal: Diversidade - Cidadania - Integração. Actas do I Congresso Imigração em Portugal: Diversidade - Cidadania - Integração. Lisboa: Acime, 2003.

SCUDELER, V. C. Imigrantes valdarenses no mercado de trabalho dos Estados Unidos. In: REIS, R. R.; SALES, T. (Org.) Cenas do Brasil migrante. São Paulo: Boitempo, 1999. p.193-232.

SOARES, W. Emigrantes e investidores: redefinindo a dinâmica imobiliária na economia valadarense. Rio de Janeiro, 1995a. Dissertação (Mestrado) - IPPUR, Universidade Federal do Rio de Janeiro.

Ser valadarense: a conquista de nova posição no espaço social e a (re)territorizalização na origem. Travessia Revista do Migrante, São Paulo, v.8, n.21, p.23-7, 1995b.

. Emigração e (i)mobilidade residencial: momentos de ruptura na reprodução/ continuidade da segregação social no espaço urbano. In: REIS, R. R.; SALES, T. (Org.) Cenas do Brasil migrante. São Paulo: Boitempo, 1999. p.167-92.

Da metáfora à substância: redes sociais, redes migratórias e migração nacional e internacional em Valadares e Ipatinga. Belo Horizonte, 2002. Tese (Doutorado em Demografia) - Universidade Federal de Minas Gerais.

THOMAZ, O. R. Ecos do Atlântico Sul: representações sobre o terceiro império português, São Paulo, 1997. Tese (Doutorado) - Faculdade de Filosofia, Letras e Ciências Humanas, Universidade de São Paulo.

TORRESAN, A. Loud and Proud: immigration and Identity in a Brazilian/Portuguese Postcolonial Encounter in Lisbon, Portugal. A thesis submitted to the University of Manchester for the degree of Doctor of Philosophy in the Faculty of Social Sciences and Law, 2004. 
VALA, J. Percepções sobre a imigração e transformações nas representações sociais sobre as diferenças entre grupos humanos. In: A Europa, o desafio demográfico e o espaço de liberdade, segurança e justiça. Lisboa: Publicações do Gabinete do Parlamento Europeu, 2003.

RESUMO - NESTE ARTIGO pretendo refletir sobre as imigrações brasileiras para Portugal e suas relações com categorias étnicas portuguesas. Levando em consideração que a localização da imigração brasileira numa hierarquia das alteridades portuguesa pressupõe uma etnização do conjunto da população migrante brasileira, procurarei demonstrar como o que se esconde sob o rótulo etnicizado de "brasileiros em Portugal" é uma população diversa e extremamente variada em suas formas de construção de identidades. Esboçarei, ainda, uma análise sobre as conseqüências políticas do discurso étnico-político no que se refere à cidadania e integração da população imigrante brasileira em Portugal.

PALAVRAS-CHAVE: Etnicidade, Migrações internacionais, Portugal, Imigração brasileira.

ABSTRACT - THIS PAPER is an excogitation on Brazilian immigration to Portugal and on the relationship between the immigrants and various Portuguese ethnic categories. Seeing that the sites chosen by Brazilian immigrants from among a hierarchy of Portuguese alterities presume an ethnization of the entire Brazilian migrant population, I have attempted to demonstrate that, hidden beneath the ethnicized label of "Brazilians in Portugal", one finds a diverse and extremely varied population in terms of how they build their identity. In addition, I have made a concise analysis of the political consequences of the ethnical-political discourse regarding the citizenship and integration of the Brazilian immigrant population in Portugal.

KEYWORDS: Ethnicity, International migrations, Portugal, Brazilian immigration.

Igor José de Renó Machado é antropólogo, professor da Universidade Federal de São Carlos (UFSCar) e pesquisador do Cemi/Unicamp. @ - igorr@unicamp.br

Recebido em 19.4.2006 e aceito em 4.5.2006. 